\title{
Rapid Assessment of Choice between Cocaine and Food in Rhesus Monkeys: Effects of Environmental Manipulations and Treatment with $d$-Amphetamine and Flupenthixol
}

\author{
S Stevens Negus*, \\ 'Alcohol and Drug Abuse Research Center, McLean Hospital, Harvard Medical School, Belmont, MA, USA
}

\begin{abstract}
The present study describes a procedure that permits rapid assessment of environmental and pharmacological factors that may influence the choice between cocaine and food in rhesus monkeys. Daily $2 \mathrm{~h}$ sessions were divided into five components. During each component, monkeys $(N=4)$ chose between i.v. cocaine $(0-0.1 \mathrm{mg} / \mathrm{kg} /$ injection) and food $(0,1$, or 3 food pellets). Up to 10 reinforcers were available during each component, and different discriminative stimuli were associated with each magnitude of each reinforcer. Cocaine choice was directly related to cocaine dose, and a cocaine choice dose-effect curve could be determined in a single experimental session. The choice between cocaine and food was influenced by the schedules of cocaine and food reinforcement, the magnitude of the food reinforcer, and the amount of noncontingent food provided outside the experimental session. These results confirm and extend previous findings with other choice procedures and validate the sensitivity of the present procedure to environmental manipulations. The choice between cocaine and food could also be influenced by treatment with candidate pharmacotherapies for cocaine abuse and dependence. The 'agonist' medication d-amphetamine produced rightward shifts in the cocaine choice dose-effect curve and decreased cocaine choice, whereas the 'antagonist' medication flupenthixol had little effect on cocaine choice. Overall, these results suggest that this choice procedure may be useful for the evaluation of both environmental determinants of cocaine use and candidate pharmacotherapies for the treatment of cocaine abuse.

Neuropsychopharmacology (2003) 28, 919-93I, advance online publication, 5 March 2003; doi:I0.1038/sj.npp. I 300096
\end{abstract}

\section{INTRODUCTION}

Drug self-administration procedures have been used extensively to study environmental and pharmacological factors that influence drug-maintained responding in the laboratory and that may influence clinical patterns of drug abuse and dependence. A common feature of drug selfadministration procedures is that subjects must perform some discrete behavior, such as pressing a response key, to receive a dose of drug (Caine et al, 1993; Mello and Negus, 1996). Usually, drug is the only reinforcer available, and the primary dependent variable is the rate of self-administration. However, it is well-established that rates of drug selfadministration may be influenced by factors other than the reinforcing effects of the self-administered drug, and as a result, rate measures are not optimal for evaluating drug reinforcement (Kelleher, 1976).

Choice procedures have been developed as potentially powerful complements to simple drug self-administration

\footnotetext{
*Correspondence: SS Negus, Alcohol and Drug Abuse Research Center, McLean Hospital, Harvard Medical School, II 5 Mill Street, Belmont, MA 02478-9106, USA, Tel: + 617855 3324, Fax: + 617 855 2519, E-mail: negus@mclean.harvard.edu

Received 17 April 2002; revised 8 October 2002; accepted 15 October 2002

Online publication: 22 October 2002 at http://www.acnp.org/citations/ Npp 102202412
}

procedures (Griffiths et al, 1976; Johanson, 1976; Woolverton and Balster, 1979; Hart et al, 2000). In choice procedures, two or more reinforcers are available simultaneously, and two or more behaviors are concurrently monitored and associated with programmed consequences. For example, responses on one key may produce drug injections, and responses on a different, concurrently available key may produce some other reinforcer, such as food. The primary dependent variable in choice procedures is the proportion of behavior allocated to each choice. This measure is relatively independent of response rate, and it has been argued that choice measures are superior to rate measures in studies of drug reinforcement (eg Griffiths et al, 1976; Johanson, 1976; Woolverton and Johanson, 1984). In addition, human drug use occurs in complex environments where many reinforcers may be available. Indeed, drug abuse and drug dependence are defined largely as pathological misallocations of behavior that favor drug use at the expense of more adaptive behaviors maintained by other reinforcers (American Psychiatric Association, 1994; Heyman, 2002). From this perspective, choice procedures may be especially well suited to the study of environmental and pharmacological factors that increase drug choice and may promote drug abuse or that decrease drug choice and may be useful in the treatment of drug abuse. 
Despite the acknowledged promise of choice procedures, one limitation to their use in preclinical studies with research animals has been the relatively slow rate of data acquisition. For example, previous choice procedures in nonhuman primates typically required several weeks to determine complete drug choice dose-effect curves (Woolverton and Balster, 1979; Nader and Woolverton, 1991). In view of this limitation and of the potential utility of choice procedures for the study of drug-maintained responding, the present study had three goals. The primary goal was to identify experimental conditions that would permit the study of choice between food and each of several cocaine doses within a single experimental session in rhesus monkeys. Such a procedure would permit a more rapid assessment of choice than has been possible with previous procedures. A second goal of the present study was to evaluate changes in cocaine $v s$ food choice produced by manipulation of three environmental variables: (1) the schedules of reinforcement for cocaine and food, (2) the magnitude of the food reinforcer available during experimental sessions, and (3) the delivery of noncontingent food or cocaine. Manipulation of some of these variables influenced the choice between cocaine and food under other conditions (Nader and Woolverton, 1991, 1992a, b). Accordingly, the validity of the present procedure was tested by examining its usefulness in confirming and extending these previous findings.

The third goal of this study was to examine the choice between cocaine and food during treatment with candidate pharmacotherapies for cocaine dependence. Choice procedures are being used with increasing frequency to evaluate candidate pharmacotherapies in human studies (Haney et al, 1998, 1999, 2001; Walsh et al, 2001), but to date, choice procedures have been used only sparingly for this purpose in preclinical research (Woolverton and Balster, 1979, 1981). In the present study, the monoamine releaser $d$ amphetamine was tested as a candidate 'agonist' medication, because it produces many cocaine-like effects (Colpaert et al, 1979; Hoffman, 2001), and because several recent clinical studies reported promising results with $d$-amphetamine maintenance in the treatment of stimulant abuse (Fleming and Roberts, 1994; Charnaud and Griffiths, 1998; White, 2000; Grabowski et al, 2001). Flupenthixol was tested as a representative 'antagonist' medication, because it is a nonselective antagonist at D1 and D2 dopamine receptors that was reported to block some abuse-related effects of cocaine (Ettenberg et al, 1982; Baker et al, 1993) and that has also been evaluated as a treatment for cocaine dependence (Soyka and DeVry, 2000; Evans et al, 2001).

\section{METHODS}

\section{Animals}

Four drug- and experimentally-naïve male rhesus monkeys (Macaca mulatta) were subjects. Monkeys weighed 7.1$9.1 \mathrm{~kg}$ and were maintained on a diet of multiple vitamins, fresh fruit, and food biscuits (Lab Diet Jumbo Monkey Biscuits, PMI Feeds, Inc., St Louis, MO). Biscuits and vitamins were provided in the morning between 9:00 and 9:30 am (unless noted otherwise), and fruit was provided in the afternoon between 5:00 and 5:30 pm. In addition, monkeys received up to $501 \mathrm{~g}$ banana-flavored pellets (Precision Primate Pellets Formula L/I Banana Flavor, PJ Noyes Co., Lancaster, $\mathrm{NH}$ ) during daily operant sessions (see below). Water was continuously available. A $12 \mathrm{~h}$ light-dark cycle was in effect (lights on from 7:00 am to 7:00 pm).

Animal maintenance and research were conducted in accordance with the guidelines provided by the NIH Committee on Laboratory Animal Resources. The facility was licensed by the United States Department of Agriculture, and protocols were approved by the Institutional Animal Care and Use Committee. The health of the monkeys was periodically monitored by consulting veterinarians. Monkeys had visual, auditory, and olfactory contact with other monkeys throughout the study. Operant procedures and foraging toys provided opportunities for environmental manipulation and enrichment. Music or nature videotapes were also played daily in animal housing rooms to provide additional environmental enrichment.

\section{Apparatus and Catheter Maintenance}

Each monkey was housed individually in a well-ventilated stainless-steel chamber $\left(65 \times 75 \times 94 \mathrm{~cm}^{3}\right)$ equipped with a custom-designed operant panel $\left(28 \times 28 \mathrm{~cm}^{2}\right)$ mounted on the front wall. Three square translucent response keys $\left(6.4 \times 6.4 \mathrm{~cm}^{2}\right)$ were arranged $2.54 \mathrm{~cm}$ apart in a horizontal row $3.2 \mathrm{~cm}$ from the top of the operant panel. Each key could be transilluminated by red or green stimulus lights (Superbright LEDs, Fairchild Semiconductor, San Jose, CA). Each housing chamber was also equipped with a pellet dispenser (Gerbrands, Model G5210, Arlington, MA) and two syringe pumps (Model B5P-lE, Braintree Scientific, Braintree, MA; or Model 980210, Harvard Apparatus, South Natick, MA), one for each lumen of the double lumen catheter. Operation of the operant panels and data collection were accomplished with microprocessors and software purchased from Med Associates Inc. (Georgia, VT).

Implantation of intravenous catheters were performed under aseptic conditions as described previously (eg Negus and Mello, 2002). One lumen of the double lumen catheter was connected to one syringe pump (the 'cocaine pump') and was used to deliver self-administered cocaine injections. The second lumen was connected to another syringe pump (the 'treatment pump'), and this lumen was used to deliver saline or treatment drugs. Except where otherwise noted, the treatment pump was programmed to deliver $0.1 \mathrm{ml}$ of solution (saline or treatment drug) every $20 \mathrm{~min}$ for $23 \mathrm{~h}$ per day for a total of 69 injections in a volume of $6.9 \mathrm{ml}$. From 9:00 am to 10:00 am, the treatment pump did not deliver infusions, and catheters and syringes were checked and refilled if necessary. The intravenous catheter was protected by a tether system consisting of a customfitted nylon vest connected to a flexible stainless-steel cable and fluid swivel (Lomir Biomedical, Malone, NY). This flexible tether system permitted monkeys to move freely in the cage. Catheter patency was periodically evaluated by i.v. administration of ketamine $(5 \mathrm{mg} / \mathrm{kg})$ or the short-acting barbiturate methohexital $(3 \mathrm{mg} / \mathrm{kg})$ through the catheter lumen. The catheter was considered to be patent if i.v. 
administration of ketamine or methohexital produced a loss of muscle tone within $10 \mathrm{~s}$.

\section{Behavioral Procedures}

Training procedures. Behavioral sessions began daily at 11:00 am and were conducted 7 days a week. Following initial shaping of key press responding for food reinforcement ( $1 \mathrm{~g}$ food pellets) and cocaine injections $(0.1 \mathrm{mg} / \mathrm{kg} /$ injection (inj) cocaine), choice training was initiated. The terminal choice schedule consisted of five 20-min response periods separated by $5 \mathrm{~min}$ timeout periods (total session duration of $120 \mathrm{~min}$ ). During all response periods, the left, food-associated key was illuminated with red stimulus lights, and completion of the FR requirement resulted in the delivery of a food pellet. In addition, Table 1 shows that different doses of cocaine were introduced in conjunction with different stimulus conditions on the right, cocaineassociated key. The cocaine doses available during the five response periods were $0,0.0032,0.01,0.032$, and $0.1 \mathrm{mg} / \mathrm{kg} /$ inj. During training, these doses were presented in ascending order, and the dose was varied by varying the duration of pump activation and the resulting volume of each injection (see Table 1). Stimulus conditions on the cocaine-associated key were also varied by flashing green stimulus lights, and the duration of the flash corresponded to the magnitude of the available cocaine dose (see Table 1). Thus, longer flashes (and shorter interflash intervals) were associated with higher available cocaine doses. Completion of the FR requirement on the cocaine-associated key resulted in delivery of the available dose of cocaine. The final values were FR100 on the food-associated key and FR10 on the cocaine-associated key for all monkeys. FR requirements were systematically manipulated later in the study (see below).

During each response period, responding on the food- or drug-associated key reset the ratio requirement on the other key, and monkeys could complete up to 10 total ratio requirements on the food- and cocaine-associated keys. Completion of each ratio requirement initiated a $30 \mathrm{~s}$ timeout, during which all stimulus lights were turned off, and responding had no scheduled consequences. During response periods when the cocaine-associated key was not

Table I Parameters for Manipulation of Cocaine Doses and Associated Stimulus Conditions on the Cocaine-Associated Response Key

\begin{tabular}{lccc}
\hline $\begin{array}{l}\text { Cocaine } \\
\text { dose } \\
\mathbf{( m g / k g / i n j )}\end{array}$ & $\begin{array}{c}\text { Pump } \\
\text { duration } \\
(\mathbf{s})\end{array}$ & $\begin{array}{c}\text { Injection } \\
\text { volume } \\
\mathbf{( m )}\end{array}$ & $\begin{array}{c}\text { Stimulus } \\
\text { conditions }\end{array}$ \\
\hline 0 & 0 & 0 & $0 \mathrm{~s}$ on $/ 3 \mathrm{~s}$ off \\
0.0032 & 0.1 & 0.01 & $0.1 \mathrm{~s}$ on $/ 2.9 \mathrm{~s}$ off \\
0.01 & 0.3 & 0.03 & $0.3 \mathrm{~s}$ on $/ 2.7 \mathrm{~s}$ off \\
0.032 & 1.0 & 0.1 & $1.0 \mathrm{~s}$ on $/ 2.0 \mathrm{~s}$ off \\
0.1 & 3.0 & 0.3 & $3.0 \mathrm{~s}$ on $/ 0 \mathrm{~s}$ off \\
\hline
\end{tabular}

Cocaine doses were varied by manipulating the amount of time the syringe pump was activated (pump duration) and the resulting injection volume. Different cocaine doses were associated with different stimulus conditions on the cocaine-associated response key. The green stimulus lights in this key were programmed to flash during repeating $3 \mathrm{~s}$ cycles, and the duration of the flash corresponded to the magnitude of the available cocaine dose. illuminated and a ' 0 ' dose of cocaine was available, responses on this key were still recorded, they still reset the FR requirement on the food-associated key, and completion of the FR requirement still counted as one of the 10 allotted ratios and initiated a $30 \mathrm{~s}$ timeout. If all 10 ratio requirements were completed before the $20 \mathrm{~min}$ response period had elapsed, then all stimulus lights were extinguished and responding had no scheduled consequences for the remainder of that 20-min response period. Choice training was considered to be complete when the $\mathrm{ED}_{50}$ value of the dose-effect curve for cocaine choice (see Data analysis) varied by less than two-fold for 3 consecutive days.

Testing procedures. Once training was completed, testing began. The variables manipulated were: (1) order of cocaine dose presentation, (2) FR value on the food-associated and cocaine-associated keys, (3) magnitude of the food reinforcer, (4) effect of noncontingent food delivery and of food restriction, (5) effect of noncontingent cocaine delivery and of restricted access to cocaine, and (6) effects of treatment with two putative pharmacotherapies for cocaine dependence, the monoamine releaser $d$-amphetamine and the nonselective dopamine receptor antagonist flupenthixol. Each manipulation was evaluated in a group of three monkeys. Preliminary studies indicated that the effects of both environmental and pharmacological manipulations usually stabilized within 3 days. As a result (except where noted otherwise), each manipulation was studied for 3 consecutive days, and data from the third day were used for data presentation and analysis. Baseline conditions for all manipulated variables are shown in Table 2, and these baseline conditions were reinstated between all experiments for at least 3 days and until choice recovered to baseline values.

The first experiment assessed choice when the order of presentation of cocaine doses was varied across the five response periods of the test session. The effects of an ascending dose order $(0-0.0032-0.01-0.032-0.1 \mathrm{mg} / \mathrm{kg} / \mathrm{inj})$, a descending order $(0.1-0.032-0.01-0.0032-0 \mathrm{mg} / \mathrm{kg} / \mathrm{inj})$, and a mixed order (0.01-0.1-0.0032-0-0.032 mg/kg/inj) were studied. In addition, the effects of making each dose available during all five response periods was studied. Regardless of the dose order, availability of any dose of cocaine was always associated with the same stimulus conditions (see Table 1). In addition, when the highest

Table 2 Baseline Conditions of Variables for Evaluation of Cocaine vs Food Choice

\begin{tabular}{ll}
\hline Variable & Baseline condition \\
\hline Cocaine dose order & Ascending $(0,0.0032,0.01$, \\
& $0.032,0.1 \mathrm{mg} / \mathrm{kg} / \mathrm{inj})$ \\
FR on food-associated key $\left(F R_{f}\right)$ & 100 \\
FR on cocaine-associated key $\left(F R_{c}\right)$ & 10 \\
Food reinforcer magnitude & One pellet \\
Feeding condition & Morning ration of biscuits, \\
& afternoon ration of fruit \\
Treatment solution & Saline
\end{tabular}

Each of the variables shown above was manipulated during the course of the study. These variables were set at the baseline values shown for initial training, and these baseline values were also reinstated between experiments. 
dose of $0.1 \mathrm{mg} / \mathrm{kg} / \mathrm{inj}$ cocaine was available during all five response periods, the maximum number of reinforcers that could be earned during each response period was reduced from 10 to 5 to avoid the possibility of cocaine overdose.

The second experiment manipulated the relative response requirements for food and cocaine. First, the FR on the food-associated key was held constant at $F R=100$, and the FR value on the cocaine-associated key was varied from FR1 to FR1000. Then the FR on the cocaine-associated key was held constant at $F R=10$, and the $F R$ value on the foodassociated key was decreased to FR10 and increased to FR1000.

The third experiment examined the effects of altering the value of the food reinforcer. Choice was evaluated when the magnitude of each food reinforcer was set at 0,1 , or 3 food pellets. Stimulus conditions on the food-associated key were varied to correspond with the different magnitudes of the food reinforcer. When zero pellets were available, the red lights in the food-associated key were not illuminated. When one pellet was available, the food-associated key was illuminated with red lights. When three food pellets were available, the food-associated key was illuminated with both red and yellow lights. To minimize the influence of food satiation when the food reinforcer magnitude was three pellets, the maximum number of reinforcers per response period was reduced from 10 to 5 (ie a maximum of 15 food pellets per response period or 75 food pellets for the entire session).

A fourth experiment examined the effects of noncontingent delivery of food or of restricted access to food. Normally, monkeys received a ration of 6-7 monkey biscuits (approximately 90-105 g of food) between 9:00 and 9:30 am and a piece of fruit between 5:00 and 5:30 pm. To assess the effects of noncontingent food delivery, an additional ration of $100 \mathrm{lg}$ food pellets (identical to those used as food reinforcers during the experimental session) was placed into the feeding cup in the monkey's cage at 10:00 am, $1 \mathrm{~h}$ before the beginning of the behavioral session. Thus, this treatment approximately doubled the dry-food ration delivered before the experimental session. To assess the effects of food restriction, two approaches were used. First, the daily ration of biscuits was reduced by $50 \%$, and it was delivered in the afternoon, 1-2 $\mathrm{h}$ after the completion of the behavioral session. In a separate 3-day experiment, the daily food ration of biscuits was discontinued, and the only food provided to monkeys outside the behavioral session was the afternoon ration of fruit.

The fifth experiment examined the effects of noncontingent delivery of cocaine or of restricted access to selfadministered cocaine. Normally, monkeys could receive cocaine daily, but only by responding on the cocaineassociated key during the behavioral session. To assess the effects of noncontingent cocaine delivery, the treatment pump was programmed to deliver a pseudo-continuous, 3 -h infusion of cocaine $(0.32,1.0$, or $1.8 \mathrm{mg} / \mathrm{kg} / \mathrm{h})$ beginning at 10:00 am and continuing throughout the behavioral session. During this treatment, $0.1 \mathrm{ml}$ cocaine injections were delivered in $1 \mathrm{~s}$ at $1 \mathrm{~min}$ intervals, for a total of $60 \mathrm{injs} / \mathrm{h}$ or 180 injections for the entire 3 -h infusion. To assess the effects of cocaine restriction, access to cocaine self-administration was suspended for 3 consecutive days in one experiment and for 7 consecutive days in a separate experiment. On these days, behavioral sessions were conducted, the red lights in the food-associated key were illuminated, and monkeys could earn food pellets by responding on the food-associated key. However, the green lights in the cocaine-associated key were not illuminated, and completion of the $\mathrm{FR}$ requirement on the cocaineassociated key did not result in the delivery of a cocaine injection. An ascending dose order of cocaine availability was then reinstated on the day after cocaine restriction.

The final experiment assessed the effects of treatment with two medications, $d$-amphetamine and flupenthixol, that have been evaluated for their utility in the treatment of cocaine dependence. Since most effective drug abuse treatment medications are either long-acting drugs or long-acting formulations of drugs (eg oral methadone or sublingual buprenorphine for the treatment of heroin dependence, nicotine patch for the treatment of nicotine dependence), the present study used drugs and methods of drug delivery designed to produce relatively sustained effects throughout the 3 -day treatment period. $d$-Amphetamine (0.01-0.1 $\mathrm{mg} / \mathrm{kg} / \mathrm{h})$ was delivered by repeated infusions via the treatment pump. As with the standard saline infusion, amphetamine was infused once every $20 \mathrm{~min}, 23 \mathrm{~h}$ per day, for a total of 69 injections in a volume of $6.9 \mathrm{ml}$. Previous studies demonstrated that i.m. administration of flupenthixol has a long duration of action in rhesus monkeys and produces long-acting changes in some effects of cocaine (eg Negus et al, 1996). Accordingly, flupenthixol (0.01-0.032 mg/ $\mathrm{kg}$ ) was administered i.m. once daily at 9:00 am.

Data analysis. The primary dependent variables for each response period were: (1) percent cocaine choice, defined as (number of ratios completed on the cocaine-associated key $\div$ total number of ratios completed) $\times 100$, (2) response rate, defined as the total number of responses $\div$ total time responses had scheduled consequences, and (3) total number of ratios completed. These variables were then plotted as a function of the dose of cocaine $(0-0.1 \mathrm{mg} / \mathrm{kg} /$ inj) or the number of the response period during the behavioral session (1-5). The $\mathrm{ED}_{50}$ value of the dose-effect curve for cocaine choice was defined as the dose of cocaine that produced $50 \%$ cocaine choice. Since the per cent drug choice was usually quantal, the $\mathrm{ED}_{50}$ value was determined by interpolation from the line connecting the two adjacent points that spanned $50 \%$ cocaine choice.

\section{Drugs}

Cocaine $\mathrm{HCl}$ was obtained from the National Institute on Drug Abuse (NIH, Bethesda, MD). $d$-Amphetamine sulfate and $c i s-(Z)$-flupenthixol diHCL were purchased from Sigma Chemical Co. (St Louis, MO). All drugs were dissolved in sterile water and filter-sterilized using a $0.22 \mu \mathrm{m}$ Millipore filter. Doses were calculated using the salt forms of the drugs given above.

\section{RESULTS}

\section{Baseline Patterns and Rates of Choice}

Figure 1 shows the dose-effect curves for per cent cocaine and food choice (top panel), response rate in responses/s 
(middle panel), and number of reinforcers delivered (bottom panel) under baseline conditions (see Table 2 for the description of 'baseline conditions'). Increasing doses of cocaine produced a dose-dependent increase in both per cent cocaine choice and number of cocaine injections delivered. There was also a cocaine dose-dependent decrease in per cent food choice, response rate, number of food pellets delivered, and total number of reinforcers delivered. When the unit dose of cocaine available for self-administration was relatively low $(0,0.0032$, or $0.01 \mathrm{mg} /$ $\mathrm{kg} / \mathrm{inj}$ ), nearly all responding was allocated to the food-associated key. Monkeys responded at high rates of approximately two responses/s and earned all available reinforcers. When a higher unit dose of $0.032 \mathrm{mg} / \mathrm{kg} / \mathrm{inj}$ cocaine was available, responding was reallocated exclusively to the cocaine-associated key. Mean response rate decreased slightly, but monkeys still earned all available reinforcers. When the highest unit dose of $0.1 \mathrm{mg} / \mathrm{kg} / \mathrm{inj}$ cocaine was available, monkeys continued to allocate all responses to the cocaine-associated key; however, response rates declined to very low levels, and
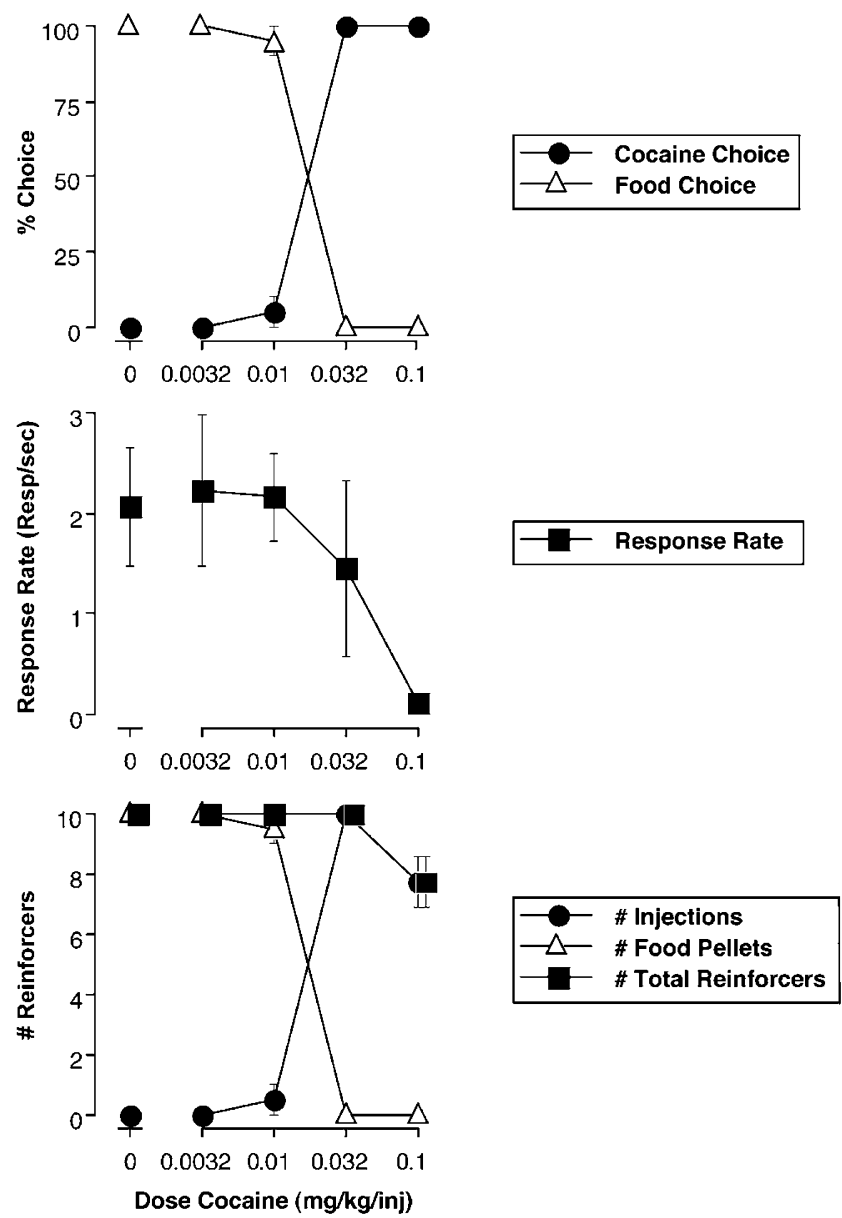

Figure I Choice under baseline conditions. Abscissae: unit dose cocaine in $\mathrm{mg} / \mathrm{kg} / \mathrm{inj}$ (log scale); top ordinate: per cent cocaine choice (filled circles) and per cent food choice (open triangles), calculated as the per cent of total FR requirements completed on the cocaine- and food-associated keys, respectively; middle ordinate: response rate in responses/s; bottom ordinate: total number of reinforcers delivered. Each point shows mean data ( \pm SEM) from three monkeys. monkeys did not always earn the maximum number of reinforcers.

\section{Stability of Choice}

Figure 2 shows that cocaine choice was stable through time and independent of the order of dose presentation. The left panels show the patterns and rates of choice determined during 3 consecutive days under baseline conditions. The dose-effect curves for per cent cocaine choice, response rate, and total number of reinforcers delivered were nearly identical for all 3 days. The center panels of Figure 2 show the effects of manipulating the order in which cocaine doses were presented during the test session. The dose-effect curves for per cent cocaine choice, response rate, and total number of reinforcers delivered were similar for ascending, descending, and mixed orders of cocaine dose presentation.

The right panels of Figure 2 show results obtained when only one dose of cocaine was available during all five response periods of the test session. As under the baseline, ascending dose-order conditions, monkeys responded almost exclusively on the food-associated key when low doses of 0 and $0.0032 \mathrm{mg} / \mathrm{kg} / \mathrm{inj}$ cocaine were available. When $0.01 \mathrm{mg} / \mathrm{kg} / \mathrm{inj}$ cocaine was available, monkeys responded almost exclusively on the food-associated key during the first three response periods, but one monkey responded primarily on the cocaine-associated key during the fourth response period, and two monkeys responded on the cocaine-associated key during the fifth response period. Thus, there was a tendency for monkeys to switch from the food-associated key to the cocaineassociated key over the course of the session during availability of $0.01 \mathrm{mg} / \mathrm{kg} / \mathrm{inj}$ cocaine. When a higher dose of $0.032 \mathrm{mg} / \mathrm{kg} / \mathrm{inj}$ cocaine was available, two monkeys responded exclusively on the cocaine-associated key throughout the session. The third monkey responded exclusively on the food-associated key during the first response period, but this monkey switched completely to the cocaine-associated key by the third response period. When the highest dose of $0.1 \mathrm{mg} / \mathrm{kg} / \mathrm{inj}$ cocaine was available, all monkeys responded exclusively on the cocaine-associated key throughout the session. Response rates were variable but usually relatively high $(>1.0$ responses/s) during availability of $0,0.0032,0.01$, and $0.032 \mathrm{mg} / \mathrm{kg} / \mathrm{inj}$ cocaine. During availability of $0.1 \mathrm{mg} / \mathrm{kg} / \mathrm{inj}$ cocaine, response rates decreased over the course of the session. However, monkeys usually earned all available reinforcers during availability of all cocaine doses. (Note that there was a maximum of five reinforcers per response period during availability of $0.1 \mathrm{mg} / \mathrm{kg} / \mathrm{inj}$ cocaine to avoid the possibility of cocaine overdose.)

\section{Effects of Manipulating the FR Requirements on the Food- and Cocaine-Associated Keys}

The dose-effect curve for per cent cocaine choice could be shifted to the left or right by manipulating the FR requirements on the cocaine- and food-associated keys. Figure 3 (left panels) shows the effects of manipulating the FR requirement on the cocaine-associated key (FRc) while holding the FR requirement on the food-associated key 

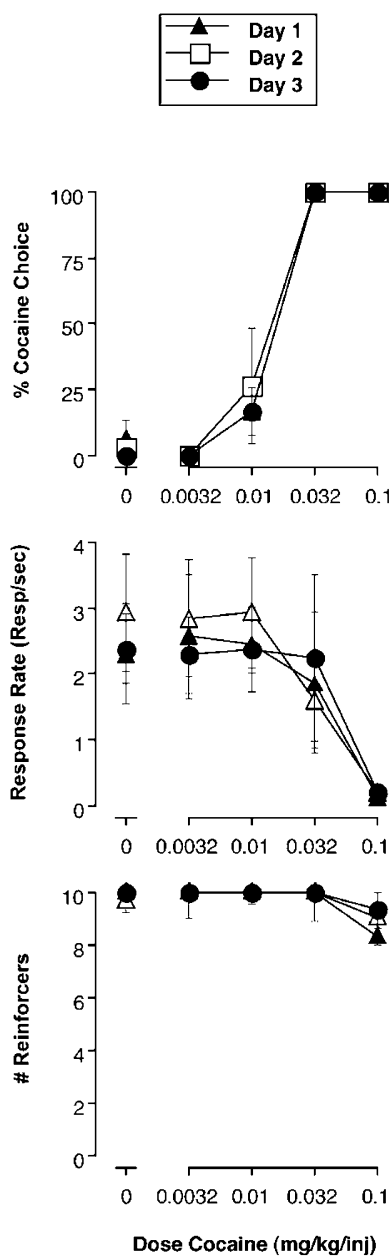

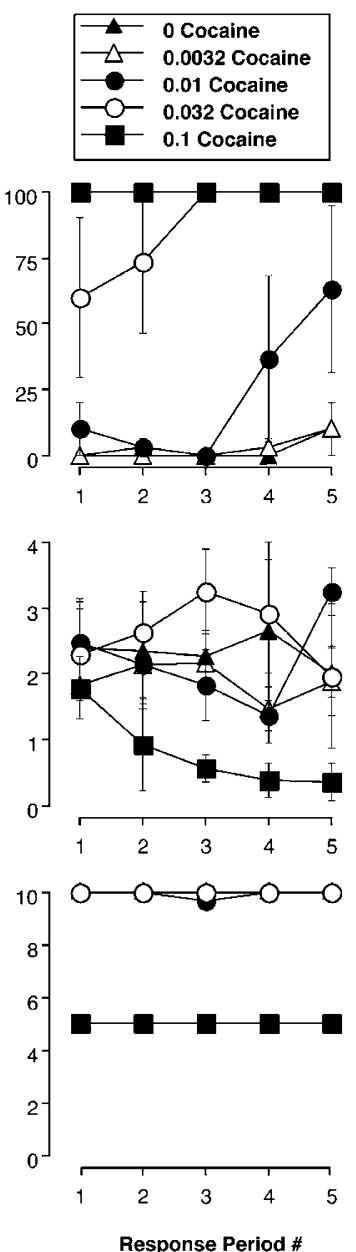

Figure 2 Stability of choice. Panels in the left column show data collected for 3 consecutive days under baseline conditions. Panels in the middle column show data collected when the order of presentation of cocaine doses was varied. Panels in the right column show data collected when only one dose of cocaine was available for all five response periods of the test session. Abscissae (left and middle panels): unit dose cocaine (log scale); abscissae (right panels): sequential number of the response period during the test session; top ordinates: per cent cocaine choice; middle ordinates: response rate in responses/s; bottom ordinates: total number of reinforcers delivered. Each point shows mean data ( \pm SEM) from three monkeys. Note that when $0.1 \mathrm{mg} / \mathrm{kg} / \mathrm{inj}$ cocaine was available throughout the session (filled squares in right panels), the maximum number for reinforcers per response period was reduced from 10 to 5.

(FRf) constant at FR100. Increasing FRc from 1 to 1000 produced ratio-dependent rightward shifts in the doseeffect curve for per cent cocaine choice. At the lowest ratio of FRc1, monkeys began to switch from the food-associated key to the cocaine-associated key at a cocaine dose of $0.01 \mathrm{mg} / \mathrm{kg} / \mathrm{inj}$. At the highest ratio of FRc1000, monkeys responded exclusively on the food-associated key throughout the session and never pressed the cocaine-associated key. These changes in choice were accompanied by modest changes in response rates and in the total number of reinforcers delivered. The greatest differences were observed during the last response period, when $0.1 \mathrm{mg} / \mathrm{kg} / \mathrm{inj}$ cocaine was available. When FRc was 1,10 , or 100, monkeys responded exclusively on the cocaine-associated key for $0.1 \mathrm{mg} / \mathrm{kg} / \mathrm{inj}$ cocaine, and response rates and total reinforcers delivered were relatively low. When FRc was 1000, monkeys responded exclusively on the food-associated key even when $0.1 \mathrm{mg} / \mathrm{kg} / \mathrm{inj}$ cocaine was available, and response rates and total reinforcers delivered were relatively high.

Figure 3 (right panels) shows the effects of manipulating FRf while holding FRc constant at FR10. Decreasing FRf to
10 produced a rightward shift in the cocaine choice doseeffect curve, and exclusive responding on the cocaineassociated key was obtained only at the highest cocaine dose of $0.1 \mathrm{mg} / \mathrm{kg} /$ inj cocaine. Increasing FRf to 1000 produced a left shift in the cocaine choice dose-effect curve, and one monkey responded on the cocaine-associated key even when the available cocaine dose was zero and the stimulus lights in the cocaine-associated key were not illuminated. Changes in FRf also affected response rates and total number of reinforcers delivered. When low doses of cocaine $(0,0.0032$, and $0.01 \mathrm{mg} / \mathrm{kg} / \mathrm{inj})$ were available and monkeys responded primarily on the food-associated key, the lowest response rates were obtained with the lowest value of FRf (FR10). Monkeys earned the maximum number of reinforcers when FRf was 10 or 100 , but total reinforcers delivered was decreased when FRf was 1000. Response rates and total reinforcers delivered also varied during availability of the higher cocaine doses $(0.032$ and $0.1 \mathrm{mg} / \mathrm{kg} / \mathrm{inj})$, when monkeys responded primarily on the cocaine-associated key. However, these rates and total reinforcers did not vary in an orderly way as a function of the FRf. 

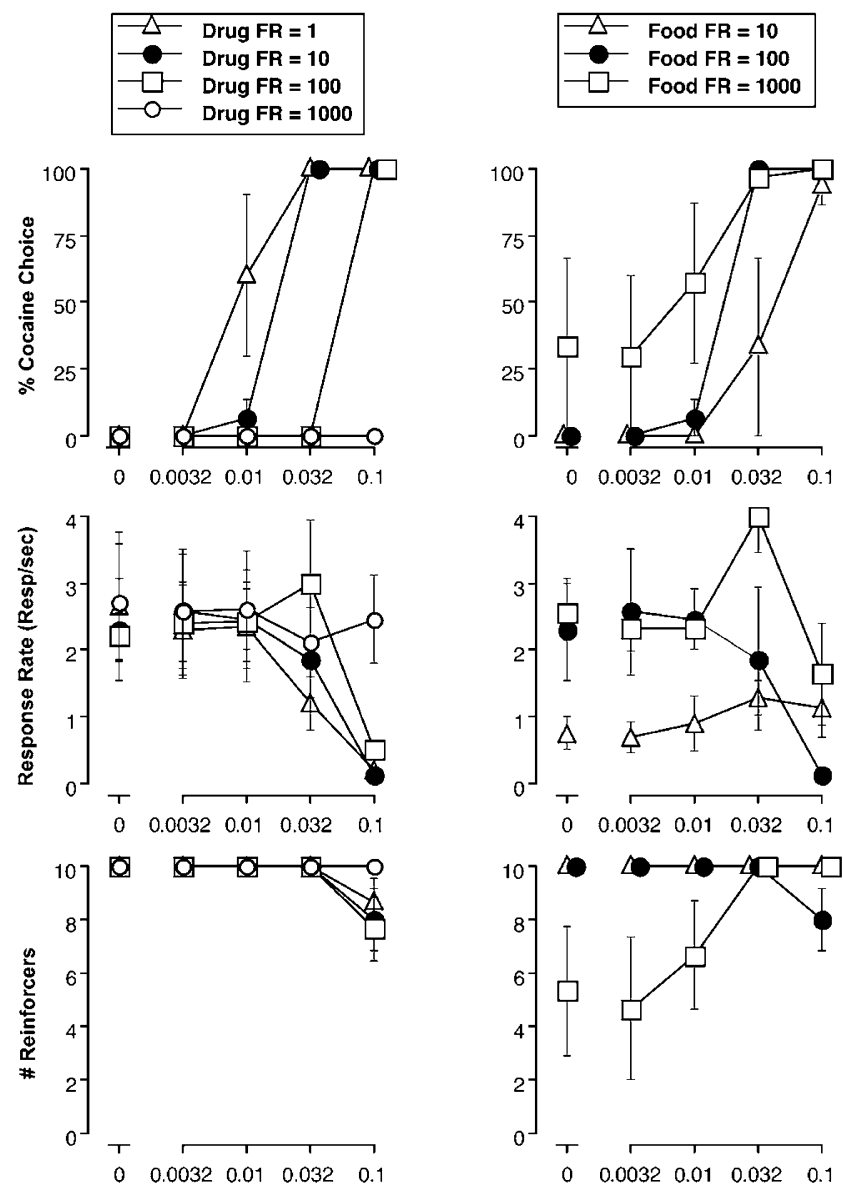

Dose Cocaine (mg/kg/inj)

Figure 3 Effects on choice of manipulating the FR requirements on the cocaine-associated key (left panels) or the food-associated key (right panels). Abscissae: unit dose cocaine in $\mathrm{mg} / \mathrm{kg} / \mathrm{inj}$ (log scale); ordinates: as in Figure 2. For results shown in the left panels, the FR requirement on the food-associated key was held constant at FR I00. For results shown in the right panels, the FR requirement on the cocaine-associated key was held constant at FRI0. Data obtained under baseline conditions are shown in the filled circles. Each point shows mean data $( \pm$ SEM) from three monkeys.

Effects of Manipulating the Food Reinforcer Magnitude and the Feeding Conditions

Figure 4 (left panels) shows the effects of changing the food reinforcer magnitude from one pellet to zero or three pellets. When the food reinforcer magnitude was reduced to zero pellets, the dose-effect curve for cocaine choice was shifted up and to the left, and monkeys responded exclusively on the cocaine-associated key. During the first response period, when no cocaine or food was available and neither response key was illuminated, two monkeys did not respond, but one monkey did respond at low rates on the cocaine-associated key. All monkeys responded on the cocaine-associated key and earned all available injections when cocaine doses were available. The cocaine dose-effect curve for response rates had an inverted $U$ shape during the 'zero pellet' condition, and peak rates of responding were observed during availability of $0.032 \mathrm{mg} / \mathrm{kg} /$ inj cocaine.
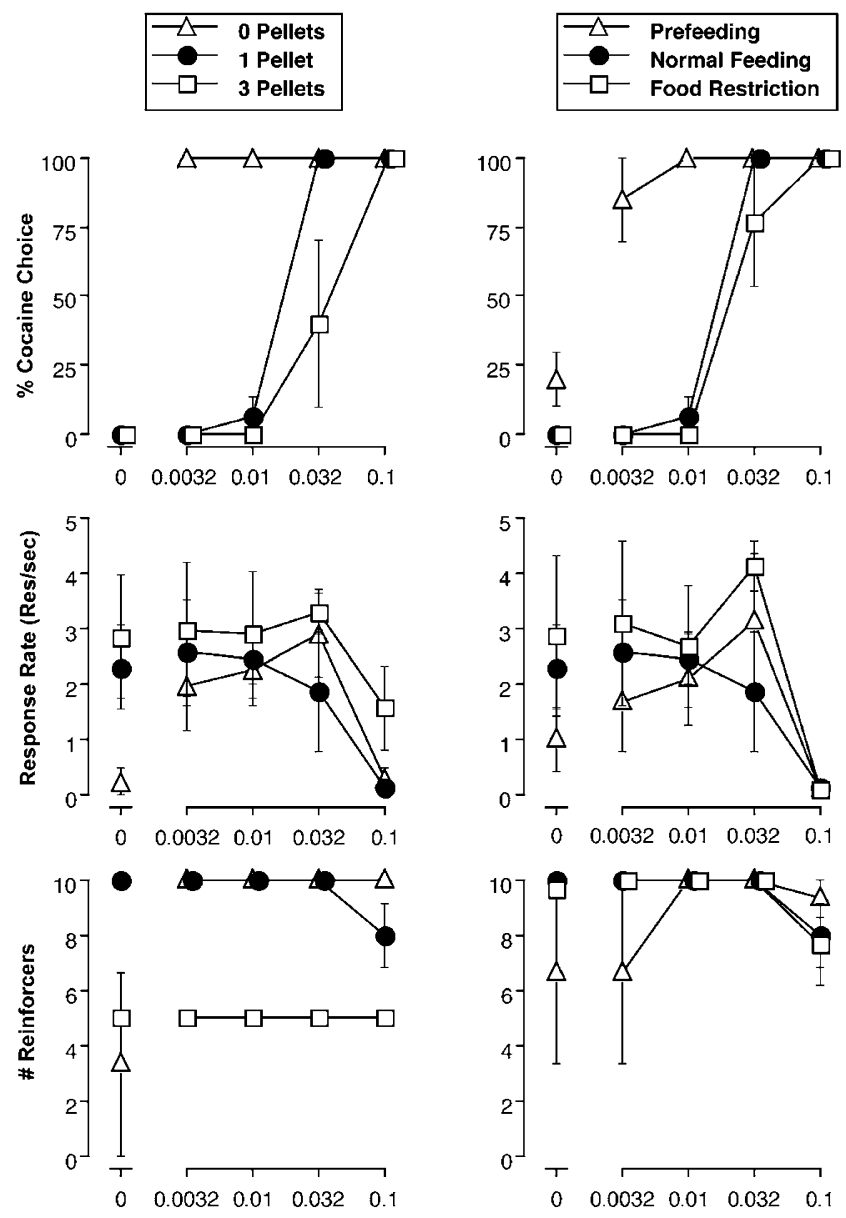

Dose Cocaine (mg/kg/inj)

Figure 4 Effects on choice of manipulating the magnitude of the food reinforcer (left panels) or the feeding condition (right panels). When the food reinforcer magnitude was 'zero pellets' (open triangles in left panels), two monkeys did not respond during availability of the ' $0 \mathrm{mg} / \mathrm{kg} / \mathrm{inj}$ ' dose of cocaine. As a result, a point for per cent cocaine choice is not plotted in the top panel. Also, when the food reinforcer magnitude was 'three pellets' (open squares in left panels), the maximum number of reinforcers per response period was reduced from 10 to 5 . All other details are as in Figure 3.

When the food reinforcer magnitude was increased to three pellets, the dose-effect curve for per cent cocaine choice was shifted to the right in two monkeys and unaffected in one monkey. Response rates were increased slightly relative to baseline conditions, and monkeys earned all available reinforcers during all response periods. (Note that there was a maximum of five reinforcers per response period during the 'three pellet' condition to minimize the influence of food satiation.)

Figure 4 (right panels) shows the effects of altering the feeding conditions. Under prefeeding conditions, monkeys received an additional ration of 100 food pellets $1 \mathrm{~h}$ prior to the session, and individual monkeys gained 0.1, 0.4, and $0.7 \mathrm{~kg}(1.3,5.8$, and $9.5 \%$ of their original body weight) during the 3-day treatment. Prefeeding shifted the doseeffect curve for per cent cocaine choice up and to the left. During the first response period, when only food was available and only the food-associated key was illuminated, 
one monkey did not respond, and two monkeys responded at low rates on both the food- and cocaine-associated keys. All monkeys responded primarily on the cocaine-associated key when cocaine doses were available. The cocaine doseeffect curve for response rates had an inverted $U$ shape during the 'prefeeding' condition, and peak rates of responding were observed during availability of $0.032 \mathrm{mg} /$ $\mathrm{kg}$ /inj cocaine.

Under food restriction conditions, the morning ration of food biscuits was discontinued, and individual monkeys lost $0,0.4$, and $0.5 \mathrm{~kg}(0,5.5$, and $6.9 \%$ of their original body weight) during the 3 -day treatment. Food restriction shifted the dose-effect curve for per cent cocaine choice to the right in the monkey that lost the most weight, but it had no effect in the other two monkeys. Response rates were increased slightly relative to baseline conditions, and total reinforcers delivered were similar to baseline conditions. The effects of a milder regimen of food restriction were also tested, in which the daily ration of biscuits was reduced by $50 \%$ and was provided to the monkeys after the behavioral session rather than before it. Under these conditions, individual monkeys lost $0,0.2$, and $0.3 \mathrm{~kg}(0,2.6$, and $4.3 \%$ of their original body weight), and the dose-effect curve for per cent cocaine choice was not affected in any monkey (data not shown).

\section{Effects of Noncontingent Cocaine and Suspended Access to Cocaine}

Figure 5 shows that noncontingent administration of $0.32 \mathrm{mg} / \mathrm{kg} / \mathrm{h}$ cocaine during the experimental session shifted the dose-effect curve for per cent cocaine responding to the right in one monkey, but it had no effect in the other two monkeys tested. Noncontingent cocaine also decreased response rates and decreased the total number of reinforcers delivered. Higher doses of 1.0 and $1.8 \mathrm{mg} / \mathrm{kg} / \mathrm{h}$ cocaine were also tested, but these doses decreased or eliminated responding and failed to produce further shifts in the dose-effect curve for per cent cocaine choice (data not shown).

Figure 5 also shows the effects of suspending access to cocaine self-administration for 7 consecutive days. Suspended access to cocaine self-administration produced a rightward shift in the dose-effect curve for per cent cocaine choice in one monkey and had no effect in the other two monkeys. Response rates and total reinforcers delivered were similar to or slightly higher than those observed under baseline conditions. A shorter 3-day period of suspended access to cocaine self-administration had no effect on the dose-effect curve for cocaine choice in any of the monkeys (data not shown).

\section{Effects of Treatment with $d$-Amphetamine and Flupenthixol}

Figure 6 (left panels) shows that continuous treatment with the monoamine releaser $d$-amphetamine produced dose-dependent rightward shifts in the dose-effect curve for per cent cocaine choice. The lowest dose of $0.01 \mathrm{mg} / \mathrm{kg} / \mathrm{h} d$-amphetamine had little effect on choice, response rates, or the total number of reinforcers delivered. However, a higher dose of $0.032 \mathrm{mg} / \mathrm{kg} / \mathrm{h} d$ -


Figure 5 Effects on choice of noncontingent cocaine infusions or of restricted access to cocaine self-administration. All other details are as in Figure 3.

amphetamine shifted the dose-effect curve for per cent cocaine choice approximately $1 / 2 \log$ units to the right in all three monkeys. Response rates and total number of reinforcers delivered were unaffected or slightly decreased by $0.032 \mathrm{mg} / \mathrm{kg} / \mathrm{h} d$-amphetamine. The highest dose of $0.1 \mathrm{mg} / \mathrm{kg} / \mathrm{h} d$-amphetamine eliminated responding in one monkey. However, in the other two monkeys, $0.1 \mathrm{mg} / \mathrm{kg} / \mathrm{h}$ $d$-amphetamine increased response rates during most response periods, and all responding was allocated to the food-associated key.

The dopamine receptor antagonist flupenthixol, in contrast, had little effect on cocaine choice (Figure 6, right panels). A low dose of $0.01 \mathrm{mg} / \mathrm{kg}$ flupenthixol produced only small leftward shifts in the dose-effect curves for per cent cocaine choice in two monkeys and had no effect in the third monkey. The low dose of $0.01 \mathrm{mg} / \mathrm{kg}$ flupenthixol had little effect on response rates, although it did increase the total number of cocaine injections delivered when the high dose of $0.1 \mathrm{mg} / \mathrm{kg} / \mathrm{inj}$ cocaine was available (mean \pm SEM inj/component was $6.67 \pm 0.88$ during saline treatment and $10.0 \pm 0$ during $0.01 \mathrm{mg} / \mathrm{kg}$ flupenthixol treatment). A higher dose of $0.018 \mathrm{mg} / \mathrm{kg}$ flupenthixol dramatically reduced response 

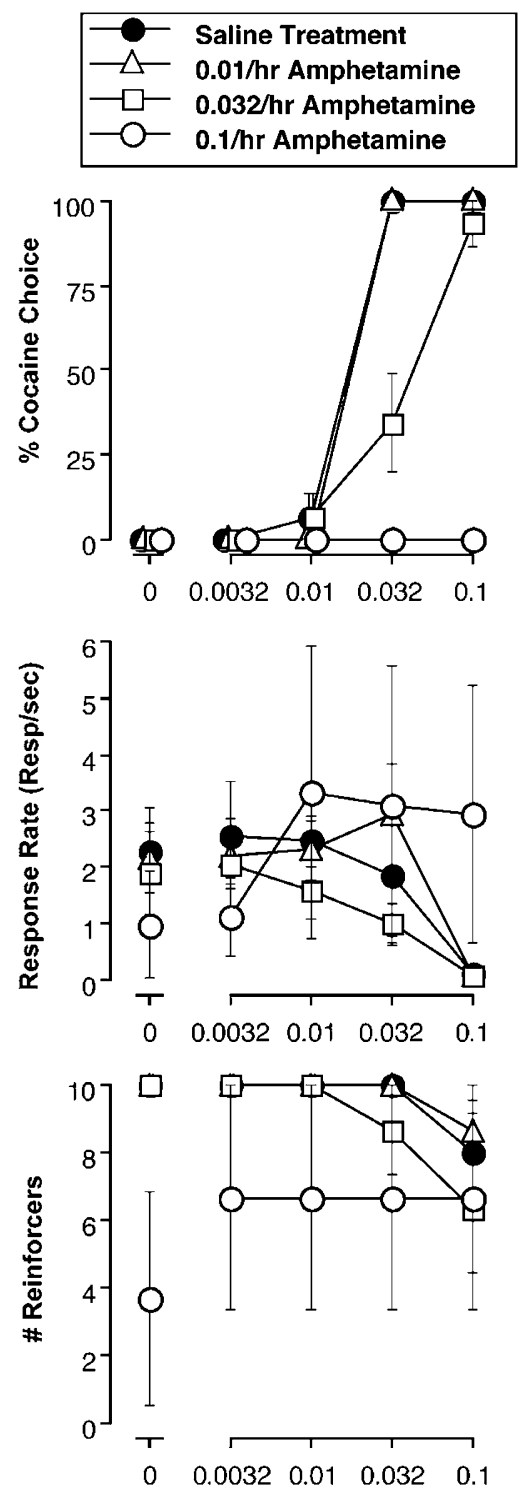


Dose Cocaine $(\mathrm{mg} / \mathrm{kg} / \mathrm{inj})$

Figure 6 Effects on choice of treatment with d-amphetamine (left panels) or flupenthixol (right panels). d-Amphetamine was administered by continuous i.v. infusion, and doses are expressed in units of $\mathrm{mg} / \mathrm{kg} / \mathrm{h}$. Flupenthixol was administered by i.m. injection, and doses are expressed in units of $\mathrm{mg} / \mathrm{kg}$. Doses of $0.1 \mathrm{mg} / \mathrm{kg} / \mathrm{h} \mathrm{d}$-amphetamine and 0.018 and $0.032 \mathrm{mg} / \mathrm{kg}$ flupenthixol eliminated responding in some monkeys during some response periods. As a result, data for per cent cocaine choice in the top panel are shown only if at least two of the three monkeys responded and earned at least one reinforcer. All other details are as in Figure 3.

rates. However, two monkeys responded during the first response period, when only food was available and only the food-associated key was illuminated, and one of these monkeys responded exclusively on the cocaine-associated key. These monkeys also responded during the last two response periods, when 0.032 or $0.1 \mathrm{mg} /$ $\mathrm{kg} / \mathrm{inj}$ cocaine was available, and all responding was allocated to the cocaine-associated key. The highest dose of $0.032 \mathrm{mg} / \mathrm{kg} / \mathrm{inj}$ flupenthixol eliminated responding during the first four response periods. However, two monkeys responded during the last response period, when $0.1 \mathrm{mg} / \mathrm{kg} / \mathrm{inj}$ cocaine was available, and both monkeys responded exclusively on the cocaine-associated key.

\section{DISCUSSION}

\section{Baseline Choice between Cocaine and Food}

The present results agree with previous findings that choice between cocaine and food in rhesus monkeys is directly related to cocaine dose and relatively independent of response rate (Aigner and Balster, 1978; Woolverton and Balster, 1979, 1981). Choice procedures have also been used to study cocaine self-administration in humans (Haney et al, 1998, 1999, 2001; Hart et al, 2000; Walsh et al, 2001) and to study choice maintained by other drugs of abuse, such as opiates and ethanol (Griffiths et al, 1976; de Wit and Chutuape, 1993; Heyman, 1993; Williams and Woods, 2000). 
The primary goal of the present study was to build on previous experience with choice procedures and identify conditions that would permit more rapid assessment of choice. Specifically, in the seminal studies of cocaine $v s$ food choice, different discriminative stimuli (ie different colors of stimulus lights) were used to signal availability of cocaine or food, and stimulus reversal experiments demonstrated that choice was not a result of color bias (Aigner and Balster, 1978; Woolverton and Balster, 1979, 1981). Although these findings demonstrated the utility of discriminative stimuli in guiding choice, the discriminative stimuli associated with different magnitudes of each reinforcer did not differ. As a result, any change in reinforcer magnitude was unsignaled, and several days were required for choice to stabilize. In addition, only one cocaine dose and one magnitude of the food reinforcer were available during each experimental session, and different experiments were required to assess the effects of changing reinforcer magnitudes. Under these conditions, it might take several weeks to determine a single dose-effect curve for cocaine choice. The present study, in contrast, used different discriminative stimuli not only for the different reinforcer types, but also for the different magnitudes of each reinforcer. With this modification in stimulus conditions, it was possible to establish stable choice between food and five different doses of cocaine in a single experimental session. Dose-effect curves for cocaine choice determined in this way were stable through time and were largely independent of the order in which doses were presented. The principal exception to this finding occurred when an intermediate dose of cocaine $(0.01$ or $0.032 \mathrm{mg} / \mathrm{kg} / \mathrm{inj}$ ) was available during all components of an experimental session. Under these conditions, monkeys sometimes responded on the food-associated key during the initial components before switching to the cocaine-associated key during later components. These findings suggested that food delivered early in the session might decrease the reinforcing efficacy of food relative to cocaine later in the session. This hypothesis was also evaluated in subsequent studies with noncontingent delivery of food (see below).

\section{Effects of Environmental Manipulations on Cocaine vs Food Choice}

Changes in FR requirements and the magnitude of the food reinforcer. The dose-effect curve for cocaine choice could be shifted to the left by decreasing the relative FR requirement for cocaine (ie decreasing the cocaine FR or increasing the food FR) or shifted to the right by increasing the relative FR requirement for cocaine (ie by increasing the cocaine FR or decreasing the food FR). These findings confirm and extend a previous study of cocaine $v s$ food choice, which showed that increases in the cocaine FR shifted the cocaine choice dose-effect curve to the right and downward (Nader and Woolverton, 1992b). That study also found that increases in the food FR increased the choice of one dose of cocaine $(0.1 \mathrm{mg} / \mathrm{kg} / \mathrm{inj})$ over food in two monkeys (Nader and Woolverton, 1992b). The present study extended this finding by demonstrating that changes in the food FR can shift the entire cocaine choice doseeffect curve.
Cocaine choice was also inversely related to the magnitude of the food reinforcer in the present study. This agrees with previous findings that the presence of an alternative reinforcer can decrease cocaine self-administration to an extent that is dependent on the magnitude of the alternative reinforcer (Carroll et al, 1989; Nader and Woolverton, 1991; Higgins, 1997; Campbell and Carroll, 2000; Hart et al, 2000). A corollary to this principle, clearly demonstrated in the context of the present study, is that a decrease in the magnitude of an alternative reinforcer may increase cocaine self-administration. The finding that changes in FR requirements and food reinforcer magnitudes produced similar results in the present study and in previous studies validates the sensitivity of this rapid assessment choice procedure to environmental manipulations.

Effects of noncontingent food and food restriction. The effect of noncontingent delivery of supplemental food pellets has not been evaluated previously in studies of cocaine $v s$ food choice. It was hypothesized that supplementing the daily ration of food with noncontingent food pellets before each experimental session would decrease the reinforcing effects of food pellets available during the session. In support of this hypothesis, prefeeding the monkeys dramatically decreased food choice and increased cocaine choice. This is consistent with the finding that food delivered during early components of a session may have decreased the reinforcing efficacy of food later in the session (see above). The present results also agree with a study that manipulated sucrose availability in rats exposed to a choice between a sucrose solution and a sucroseethanol mixture (Heyman, 1993). In that study, prefeeding rats with sucrose decreased sucrose choice and increased choice of the sucrose-ethanol mixture. Taken together, these findings suggest that delivery of a food reinforcer at one point in time can produce a selective decrease in the reinforcing effects of that food reinforcer at later points in time without decreasing the reinforcing effects of a concurrently available drug reinforcer.

It was also hypothesized that food restriction would increase the reinforcing effects of food pellets available during the session. However, food restriction was relatively ineffective in altering cocaine choice. Similarly, in a previous study, monkeys displayed an almost exclusive choice for cocaine $(0.3 \mathrm{mg} / \mathrm{kg} / \mathrm{inj})$ over food over a period of 8 days, even though monkeys received no supplemental food and lost $6-10 \%$ of their body weight (Aigner and Balster, 1978). In another study, food restriction decreased cocaine choice and produced rightward or downward shifts in cocaine choice dose-effect curves, but even in that study the effects of food restriction were modest in two of the three monkeys tested (Nader and Woolverton, 1992a). Moreover, food restriction alone was not sufficient to decrease choice for high doses of cocaine, and protocol modifications were implemented to encourage monkeys to respond for food (Nader and Woolverton, 1992a). Overall, these results suggest that cocaine vs food choice is relatively resistant to regimens of food restriction that might be expected to increase the reinforcing effects of food.

There are at least two possible explanations for the small effects of food restriction on cocaine choice. First, it is 
possible that more severe food restriction or a longer period of food restriction might have produced greater decreases in cocaine choice. For example, in the present study, food restriction produced the greatest decrease in cocaine choice in the monkey that lost the most weight. However, decreases in body weight did not correlate with decreases in cocaine choice in previous studies, even when monkeys lost up to $10 \%$ of their body weight (Aigner and Balster, 1978; Nader and Woolverton, 1992a). More severe regimens of food restriction were not examined in the present study out of concern for the health of the monkeys. A second possibility is that food restriction may increase the reinforcing effects of cocaine (Carroll, 1985) as well as those of food. As a result, food restriction may have little effect on the relative reinforcing efficacies of cocaine and food and little effect on the corresponding choices between these two reinforcers.

Effects of noncontingent cocaine and restricted access to cocaine. In contrast to the dramatic effects on cocaine choice produced by noncontingent delivery of food pellets, noncontingent delivery of cocaine injections had little effect on cocaine choice. The modest effects of noncontingent cocaine delivery on cocaine choice were probably not a result of inadequate dosing, because cocaine was tested up to doses that eliminated or substantially decreased responding in all monkeys. Rather, these findings suggest that cocaine produced a nonselective decrease in the ability of the monkeys to perform the key-press responses or a nonselective decrease in the reinforcing effects of both cocaine and food. In agreement with this conclusion, previous studies that examined cocaine- and food-maintained responding independently also found that acute, noncontingent cocaine decreased high-dose cocaine selfadministration only at doses that also decreased foodmaintained responding (Glowa and Fantegrossi, 1997; Panlilio et al, 1998).

Since cocaine was only available during experimental sessions, the only way to restrict access to cocaine was to suspend cocaine availability during experimental sessions. As with restricted access to food, restricted access to cocaine had little effect on cocaine choice. Previous preclinical studies have not systematically examined the effects of suspended cocaine access on drug self-administration in choice procedures. However, similar to the present findings, suspended access to cocaine self-administration for 10 days either did not alter or slightly decreased cocaine self-administration in rats (Mutschler et al, 2001).

\section{Effects of Treatment with Candidate Pharmacotherapies}

A final goal of the present study was to examine the effects of candidate 'agonist' and 'antagonist' medications on the choice between cocaine and food. The most straightforward 'agonist' medication for cocaine abuse would be cocaine itself, but as noted above, treatment with cocaine for $3 \mathrm{~h} /$ day decreased response rates but did not consistently decrease cocaine choice. However, the experiment described above with noncontingent cocaine was designed to parallel the prefeeding study in its temporal parameters, and these temporal parameters may not be optimal for evaluation of candidate pharmacotherapies. Specifically, medications for the treatment of drug abuse are usually either long-acting drugs or drug formulations that produce sustained actions at their pharmacological targets (eg oral methadone and $1-\alpha-$ acetylmethadol, sublingual buprenorphine, nicotine patch). To address this issue, the monoamine releaser $d$-amphetamine was tested as a representative 'agonist' medication, because it produces many cocaine-like effects and has a longer duration of action than cocaine (Colpaert et al, 1979; Hoffman, 2001). In addition, $d$-amphetamine was administered by repeated infusions for $23 \mathrm{~h}$ /day to assure a sustained action. Under these conditions, $d$-amphetamine produced a dose-dependent decrease in cocaine choice and a reallocation of responding to the food choice. These results closely parallel the results of a recent double-blind, placebo-controlled clinical study, which found that oral $d$ amphetamine (15-60 mg twice daily, or approximately 0.4$1.7 \mathrm{mg} / \mathrm{kg} /$ day) dose-dependently decreased measures of cocaine use in stimulant abusers (Grabowski et al, 2001). In that study, retention was highest at the intermediate doses of $15-30 \mathrm{mg} / \mathrm{day}$, and the higher $d$-amphetamine doses produced undesirable effects, such as insomnia and muscle twitching, that decreased retention. Other studies have also reported that maintenance on $d$-amphetamine decreased stimulant abuse (Fleming and Roberts, 1994; Charnaud and Griffiths, 1998; White, 2000; Shearer et al, 2001). The present results also parallel the finding that continuous treatment with methadone decreased heroin choice in baboons trained to choose between heroin and food (Griffiths et al, 1976). Taken together, these results are consistent with the possibility that sustained treatment with 'agonist' medications may decrease the reinforcing effects of cocaine and have some utility in treating cocaine abuse and dependence.

In contrast to the effects of $d$-amphetamine, the nonselective D1 and D2 dopamine receptor antagonist flupenthixol had little effect on cocaine choice. Many previous studies have examined the effects of flupenthixol and other dopamine antagonists on cocaine self-administration under conditions in which cocaine was the only reinforcer available at a given time, and rate measures provided the primary dependent variable (Bergman et al, 1990; Caine and Koob, 1994; Winger, 1994; Negus et al, 1996; Schenk et al, 1999; Caine et al, 2002; see Mello and Negus, 1996 for a review). In some of these studies, dopamine antagonists produced rightward shifts in cocaine dose-effect curves suggestive of an antagonist effect; however, it has repeatedly been argued that these rightward shifts may have reflected interactions between the effects of cocaine and dopamine antagonists on response rates rather than a dopamine antagonist-induced blockade of the reinforcing effects of cocaine (Herling and Woods, 1980; Bergman et al, 1990; Mello and Negus, 1996; Caine et al, 2002). The present results further support the conclusion that dopamine antagonists do not selectively block the reinforcing effects of cocaine. Although flupenthixol dosedependently decreased response rates, it did not produce a rightward shift in the rate-independent dose-effect curve for cocaine choice. Indeed, there was a tendency for flupenthixol treatment to slightly increase cocaine choice. These findings are also consistent with other preclinical and clinical findings. For example, in rhesus monkeys trained to 
choose between food and a single dose of cocaine $(0.1 \mathrm{mg} /$ $\mathrm{kg} / \mathrm{inj}$ ), cocaine choice increased during treatment with the dopamine antagonists chlorpromazine and haloperidol (Woolverton and Balster, 1981). Similarly, maintenance on flupenthixol (Evans et al, 2001) and other dopamine antagonists (Grabowski et al, 2000; Haney et al, 2001) either did not change or increased cocaine self-administration in human laboratory studies or cocaine use in clinical populations of cocaine users. Taken together, these results suggest that dopamine antagonists in general, and flupenthixol in particular, may not be useful treatments for cocaine dependence.

\section{SUMMARY}

In summary, this series of studies evaluated the effects of a range of environmental and pharmacological manipulations in a procedure designed to provide rapid assessment of choice between food and multiple doses of cocaine in rhesus monkeys (Table 3). Cocaine choice could be increased by (1) making large cocaine doses available, (2) decreasing the relative response requirement for cocaine, (3) decreasing the size of the alternative food reinforcer, or (4) providing the alternative food reinforcer in abundance (which may decrease the reinforcing efficacy of the food). Treatment with the dopamine receptor antagonist flupenthixol also tended to produce small increases in cocaine choice. Alternatively, cocaine choice could be decreased by (1) decreasing the magnitude of cocaine doses available, (2) increasing the relative response requirement for cocaine, (3) increasing the magnitude of the food reinforcer, or (4) treating monkeys with the candidate 'agonist' medication $d$-amphetamine. It is interesting to speculate about the degree to which these laboratory findings might have meaningful parallels to manipulations that promote or

Table 3 Summary of the Effects of Various Manipulations on Cocaine Choice in Individual Monkeys

\begin{tabular}{|c|c|c|c|}
\hline \multirow[b]{2}{*}{ Manipulation } & \multicolumn{3}{|c|}{ Effect on cocaine choice } \\
\hline & Increase & $\begin{array}{c}\text { No } \\
\text { effect }\end{array}$ & Decrease \\
\hline Increase cocaine dose & 3 & - & - \\
\hline Decrease $\mathrm{FR}_{c}$ /increase $\mathrm{FR}_{\mathrm{f}}$ & 3 & - & - \\
\hline Decrease food magnitude & 3 & - & - \\
\hline Prefeed & 3 & - & - \\
\hline Flupenthixol treatment & 2 & 1 & - \\
\hline Changing dose order & - & 3 & - \\
\hline Food restriction & - & 2 & I \\
\hline Noncontingent cocaine & - & 2 & । \\
\hline Suspended access to cocaine & - & 2 & i \\
\hline Decrease cocaine dose & - & - & 3 \\
\hline Increase $\mathrm{FR}_{\mathrm{c}} /$ decrease $\mathrm{FR}_{\mathrm{f}}$ & - & - & 3 \\
\hline Increase food magnitude & - & I & 2 \\
\hline Amphetamine treatment & - & - & 3 \\
\hline \multicolumn{4}{|c|}{$\begin{array}{l}\text { Each manipulation was evaluated in a group of three monkeys, and columns } \\
\text { show the number of monkeys in which each type of effect was observed relative } \\
\text { to the baseline dose-effect curve for per cent cocaine choice. Manipulations are } \\
\text { divided into those that primarily increased cocaine choice or produced leftward } \\
\text { shifts in cocaine choice dose-effect curves, those that primarily had no effect, } \\
\text { and those that primarily decreased cocaine choice or produced rightward shifts } \\
\text { in cocaine choice dose-effect curves. }\end{array}$} \\
\hline
\end{tabular}

discourage drug use and abuse in humans. For example, drug use and drug abuse often flourish when drugs are inexpensive and readily available in high dose forms, and when alternative reinforcers are either very scarce (poverty) or very abundant (wealth). Alternatively, many government policies seek to limit drug abuse by limiting drug availability (eg by controlling drug production or distribution) and increasing the cost of drugs (eg by taxing legal drugs). Similarly, drug abuse treatments often employ both agonist medications (eg methadone, nicotine) and contingency management techniques that decrease the price of alternative reinforcers (eg by providing vouchers to reward drug abstinence). Overall, these results suggest that this cocaine $v s$ food choice procedure may be a useful tool for evaluating both environmental determinants of cocaine use and candidate pharmacotherapies for the treatment of cocaine abuse.

\section{ACKNOWLEDGMENTS}

This work was supported by Grants RO1-DA02519 and P01DA14528 from the National Institute on Drug Abuse, National Institutes of Health. I thank Brooke Wurrey for outstanding technical support, Kevin Costa for writing the computer programs used in this study, and Drs Barak Caine, Gene Heyman, and Nancy Mello for their comments on an earlier version of the manuscript.

\section{REFERENCES}

Aigner TG, Balster RL (1978). Choice behavior in rhesus monkeys: cocaine versus food. Science 201: 534-535.

American Psychiatric Association (1994). Diagnostic and Statistical Manual of Mental Disorders, 4th edn (DSM-IV). American Psychiatric Association: Washington, DC.

Baker L, Riddle E, Saunders R, Appel J (1993). The role of monoamine reuptake in the discriminative stimulus effects of cocaine and related compounds. Behav Pharmacol 4: 69-79.

Bergman J, Kamien JB, Spealman RD (1990). Antagonism of cocaine self-administration by selective dopamine D1 and D2 antagonists. Behav Pharmacol 1: 355-363.

Caine SB, Koob GF (1994). Effects of dopamine $D_{1}$ and $D_{2}$ antagonists on cocaine self-administration under different schedules of reinforcement in the rat. J Pharmacol Exp Ther 270: 209-218.

Caine SB, Lintz R, Koob GF (1993). Intravenous drug selfadministration techniques in animals. In: Sahgal A (ed). Behavioral Neuroscience: A Practical Approach. Oxford University Press: Oxford. pp 117-143.

Caine SB, Negus SS, Mello NK, Patel S, Bristow L, Kulagowwski J et al (2002). Role of dopamine D2-like receptors in cocaine selfadministration: studies with D2 receptor mutant mice and novel D2 receptor antagonists. J Neurosci 22: 2977-2988.

Campbell UC, Carroll ME (2000). Reduction of drug selfadministration by an alternative non-drug reinforcer in rhesus monkeys: magnitude and temporal effects. Psychopharmacology 148: 418-425.

Carroll ME (1985). The role of food deprivation in the maintenance and reinstatement of cocaine-seeking behavior in rats. Drug Alcohol Depend 16: 95-109.

Carroll ME, Lac ST, Nygaard SL (1989). A concurrently available nondrug reinforcer prevents the acquisition or decreases the maintenance of cocaine-reinforced behavior. Psychopharmacology 97: 23-29. 
Charnaud B, Griffiths V (1998). Levels of intravenous drug misuse among clients prescribed oral dexamphetamine or oral methadone: a comparison. Drug Alcohol Depend 52: 79-84.

Colpaert FC, Niemegeers CJE, Janssen PAJ (1979). Discriminative stimulus properties of cocaine: neuropharmacological characteristics as derived from stimulus generalization experiments. Pharamcol Biochem Behav 10: 535-546.

de Wit H, Chutuape MA (1993). Increased ethanol choice in social drinkers following ethanol preload. Behav Pharmacol 4: 29-36.

Ettenberg A, Pettit HO, Bloom FE, Koob GF (1982). Heroin and cocaine intravenous self-administration in rats: mediation by separate neural systems. Psychopharmacology (Berlin) 78: 204-209.

Evans SM, Walsh SL, Levin FR, Foltin RW, Fischman MW, Bigelow GE (2001). Effect of flupenthixol on subjective and cardiovascular responses to intravenous cocaine in humans. Drug Alcohol Depend 64: 271-283.

Fleming PM, Roberts D (1994). Is the prescription of amphetamine justified as a harm reduction measure? $J R$ Soc Health 114: 127-131.

Glowa JR, Fantegrossi WE (1997). Effects of dopaminergic drugs on food- and cocaine-maintained responding. IV. Continuous cocaine infusions. Drug Alcohol Depend 45: 71-79.

Grabowski J, Rhoades H, Schmitz J, Stotts A, Daruzska LA, Creson D (2001). Dextroamphetamine for cocaine dependence treatment: a double-blind randomized clinical trial. J Clin Psychopharmacol 21: 522-526.

Grabowski J, Rhoades H, Silverman P, Schmitz J, Stotts A, Creson D (2000). Risperidone for the treatment of cocaine dependence: randomized, double-blind trial. J Clin Psychopharmacol 20: 305-310.

Griffiths RR, Wurster RM, Brady JV (1976). Discrete-trial choice procedure: effects of nalxone and methadone on choice between food and heroin. Pharmacol Rev 27: 357-365.

Haney M, Collins ED, Ward AS, Foltin RW, Fischman MW (1999). Effect of a selective dopamine D1 agonist (ABT-431) on smoked cocaine self-administration in humans. Psychopharmacology 143: $102-110$.

Haney M, Foltin RW, Fischman MW (1998). Effects of pergolide on intravenous cocaine self-administration in men and women. Psychopharmacology 137: 15-24.

Haney M, Ward AS, Foltin RW, Fischman MW (2001). Effects of ecopipam, a selective dopamine D1 antagonist, on smoked cocaine self-administration by humans. Psychopharmacology 155: 330-337.

Hart CL, Haney M, Foltin RW, Fischman MW (2000). Alternative reinforcers differentially modify cocaine self-administration by humans. Behav Pharmacol 11: 87-91.

Herling S, Woods JH (1980). Chlorpromazine effects on cocainereinforced responding in rhesus monkeys: reciprocal modification of rate-altering effects of drugs. J Pharmacol Exp Ther 214: 354-361.

Heyman GM (1993). Ethanol regulated preference in rats. Psychopharmacology 112: 259-269.

Heyman GM (2002). Drug use and abuse: cultural concerns. Int Enc Soc Behav Sci, in press.

Higgins ST (1997). Influence of an alternative reinforcer on human cocaine self-administration: a brief review. Pharmacol Biochem Behav 57: 419-427.

Hoffman B (2001). Catecholamines, sympathoemetic drugs, and adrenergic receptor antagonists. In: Hardan JG, Limbird LE (eds). The Pharmacological Basis of Therapeutics. McGraw-Hill: New York. pp 215-268.

Johanson CE (1976). Pharmacological and environmental variables affecting drug preference in rhesus monkeys. Pharmacol Rev 27: 343-355.
Kelleher RT (1976). Characteristics of behavior controlled by scheduled injections of drugs. Pharmacol Rev 27: 307-323.

Mello NK, Negus SS (1996). Preclinical evaluation of pharmacotherapies for treatment of cocaine and opioid abuse using drug self-administration procedures. Neuropsychopharmacology 14: 375-424.

Mutschler NH, Covington HE, Miczek KA (2001). Repeated selfadministered cociane 'binges' in rats: effects on cocaine intake and withdrawal. Psychopharmacology 154: 292-300.

Nader MA, Woolverton WL (1991). Effects of increasing the magnitude of an alternative reinforcer on drug choice in a discrete-trials choice procedure. Psychopharmacology 105: 169-174.

Nader MA, Woolverton WL (1992a). Choice between cocaine and food by rhesus monkeys: effects of conditions of food availability. Behav Pharmacol 3: 635-638.

Nader MA, Woolverton WL (1992b). Effects of increasing response requirement on choice between cocaine and food in rhesus monkeys. Psychopharmacology 108: 295-300.

Negus SS, Mello NK (2002). Effects of mu-opioid agonists on cocaine- and food-maintained responding and cocaine discrimination in rhesus monkeys: role of mu-agonist efficacy. $J$ Pharmacol Exp Ther 300: 1111-1121.

Negus SS, Mello NK, Lamas X, Mendelson JH (1996). Acute and chronic effects of flupenthixol on the discriminative stimulus and reinforcing effects of cocaine in rhesus monkeys. $J$ Pharmacol Exp Ther 278: 879-890.

Panlilio LV, Goldberg SR, Gilman JP, Jufer R, Cone EJ, Schindler CW (1998). Effects of delivery rate and non-contingent infusion of cocaine on cocaine self-administration in rhesus monkeys. Pychopharmacology 137: 253-258.

Schenk S, Partridge B, Shippenberg TS (1999). U69, 593, a kappaopioid agonist, decreases cocaine self-administration and decreases cocaine-produced drug-seeking. Psychopharmacology 144: 339-346.

Shearer J, Wodak A, Mattick RP, van Beek I, Lewis J, Hall W (2001). Pilot randomized controlled study of dexamphetamine substitution for amphetamine dependence. Addiction 96: 1289-1296.

Soyka M, DeVry J (2000). Flupenthixol as a potential pharmacotreatment of alcohol and cocaine abuse/dependence. Eur Neuropschopharmacol 10: 325-332.

Walsh SL, Geter-Douglas B, Strain EC, Bigelow GE (2001). Enadoline and butorphanol: evaluation of kappa-agonists on cocaine pharmacodynamics and cocaine self-administration in humans. J Pharmacol Exp Ther 299: 147-158.

White R (2000). Dexamphetamine substitution in the treatment of amphetamine abuse: an initial investigation. Addiction 95: 229-238.

Williams KL, Woods JH (2000). A behavioral economic analysis of concurrent ethanol- and water-reinforced responding in different preference conditions. Alcohol Clin Exp Res 24: 7980-986.

Winger G (1994). Dopamine antagonist effects on behavior maintained by cocaine and alfentanil in rhesus monkeys. Behav Pharmacol 5: 141-152.

Woolverton WL, Balster RL (1979). The effects of lithium on choice between cocaine and food in the rhesus monkey. Commun Psychopharmacol 3: 309-318.

Woolverton WL, Balster RL (1981). Effects of antipsychotic compounds in rhesus monkeys given a choice between cocaine and food. Drug Alcohol Depend 8: 69-78.

Woolverton WL, Johanson CE (1984). Preference in rhesus monkeys given a choice between cocaine and d, l-cathinone. $J$ Exp Anal Behav 41: 35-43. 